
\title{
25 Research Square \\ The Effect of Earth-air Passive Breathing on the Formation of Haze Patterns
}

\author{
Hongshou Li ( $\nabla$ dhlhs69@163.com ) \\ Dunhuang academy https://orcid.org/0000-0001-8588-122X \\ Yipu Gong \\ Dunhuang Academy \\ Shunren Wang \\ Dunhuang Research Academy \\ Qinglin Guo \\ Dunhuang Research Academy
}

\section{Research Article}

Keywords: earth-air, haze pattern, fine particulate concentration, PM2.5

Posted Date: April 20th, 2021

DOI: https://doi.org/10.21203/rs.3.rs-349587/v1

License: @ (i) This work is licensed under a Creative Commons Attribution 4.0 International License. Read Full License 


\section{Abstract}

As urbanization and economic growth in developing countries expands, haze has become a global environmental problem in urban areas. Haze has obvious seasonal and diurnal variations across the globe. The concentration of fine particulate matter is higher in winter and lower in summer, and its diurnal variation shows bimodal characteristics. However, the formation mechanism of this pattern is still not well understood. In this paper, the coupling between earth-air and fine particulate concentration is studied. Monitoring results have shown that the earth-air pressure generally fluctuates with the overall atmospheric pressure. There is a mechanism of 'passive breathing' of the earth-air, and due to the effect of seasonal/diurnal changes in soil temperature, 'autonomous breathing' also exists. The magnitude of the autonomous breathing effect is small $(3.57 \mathrm{~mm} / \mathrm{d})$, whereas the passive breathing effect is much larger $(421.25 \mathrm{~mm} / \mathrm{d})$. The correlation coefficients between volume of earth-air passive breathing and $\mathrm{PM}_{2.5}$ on yearly and daily timescales are 0.82 and 0.84 respectively. Statistical analysis suggests that when the atmospheric pressure rises, the atmospheric air is compressed, and concentration increases. At the same time, a part of the atmosphere enters the soil and causes back-mixing. When the atmospheric pressure drops, the atmospheric air expands, and the filtered earth-air enters the atmosphere, reducing the near-surface $\mathrm{PM}_{2.5}$ concentration. This results in the $\mathrm{PM}_{2.5}$ concentration changing synchronously with the earth-air passive breathing. Therefore, the passive breathing of earth-air has important impact on the formation of haze patterns, and the atmospheric pumping effect provides the main driving force.

\section{Introduction}

In general, underdeveloped regions commonly suffer from high concentration of fine particulate matter as a result of rapid increases in urbanization and economic growth (He et al., 2018). This situation is similar to the problems previously experienced by developed countries (Seinfeld, 2004; Paul and Panos, 2011). In recent years, severe haze events have occurred rather frequently in developing countries, such as China (Fontes et al., 2017; Liang et al., 2016) and India (Kumar, 2018; Miyazaki et al., 2009), causing serious environmental problems (Song et al., 2014a).

Various studies have explored the occurrence of haze and mechanisms responsible for its cause (Yang et al., 2015). Over the past 30 years, concentrations of fine particulate matter have been widely monitored, including the spatial and temporal distribution (Su et al., 2015; Hao and Guo, 2018; Zhao et al., 2009), especially their annual and diurnal variation which has developed clear patterns (Weingartner et al., 1999; Kim et al., 2002; Matthew et al., 2004; Xu et al., 2013; Cheng et al., 2016; Saxena et al., 2017; Manning et al., 2018; Miao et al., 2016). Hazy days mainly occur in winter, and the concentration of fine particulate matter is higher during winter/night and lower in the summer/daytime (Song et al., 2014b; Li et al., 2017).

The formation of haze is influenced by a complex combination of effects from both anthropogenic (Li et al., 2018) and natural sources (Song et al., 2014b; Sun et al., 2014; Zhang et al., 2018). Vehicular emissions, coal burning, biomass burning, oil burning, and industry are important sources of $\mathrm{PM}_{2.5}$ and $\mathrm{PM}_{10}$ pollutants (particulate matter with aerodynamic diameters less than 2.5 or $10 \mu \mathrm{m}$ ) and aerosols 
(Masiol et al., 2016). However, the research on the dynamical foundation and mechanism responsible for the haze pattern formation is insufficient, which hinders the forecasting and control of haze pollution (Tie et al., 2017; Wang et al., 2016).

Haze studies, however, ignore the effect of the earth-air in connection with the atmosphere. Here, the term 'earth-air' refers to the air contained in the soil below the earth's surface. Earth-air fluctuates with the external atmospheric pressure, giving rise to 'passive breathing' (Nilson et al., 1991). This atmospheric pumping effect influences the volume of the earth-air below ground. Furthermore, the latest research findings of the present author proved that 'autonomous breathing' on daily and yearly timescales because of the earth's motion and periodic fluctuations in the temperature of the soil (Li, 2018). Therefore, earth-air breathing is a universal phenomenon that occurs globally (Li and Zhan, 2018). The movement of earth-air has a significant impact on evaporation, which increases the phreatic evaporation by three orders of magnitude (Li et al., 2021). However, its impact on the haze pattern has not been well studied.

In this paper, monitoring results of the earth-air pressure and temperature were used to quantitatively estimate the contribution made by autonomous and passive breathing to the volume of exchanged air. We thus investigated the role of earth-air plays in the formation of haze patterns. The aim was to reveal the formation mechanism of haze pattern from the innovative aspect of earth-air, and provide a scientific basis for haze prevention and control.

\section{Methodology}

To deduce the level of correlation between earth-air breathing and haze pattern formation, we need to obtain representative data for the variation in the concentration of fine particulate matter on daily and yearly timescales. At the same time, we must obtain the commensurate variation in the earth-air breathing on the same timescales, which can represent the pattern of earth-air changes on a global scale. Statistical methods can then be used to study the correlation between fine particulate concentration and earth-air breathing. In addition, through the fitting formula of pressure change obtained by closed laboratory experiment $(\mathrm{Li}, 2018)$ and gas equation, quantitative estimates the volume of diurnal and annual earth-air breathing. Then, we can use physics and chemistry principles to analyze the effect of earth-air in the formation of the haze pattern, and revealed the mechanism involved.

\subsection{Annual and diurnal variations in concentration of fine particulate matter}

In this work, we use data recorded by China's Air Quality Monitoring and Analysis Platform, which can be queried online to obtain historical data including $\mathrm{PM}_{2.5 / 10}, \mathrm{SO}_{2}$, and $\mathrm{NO}_{2}$ concentrations (https://www.aqistudy.cn/historydata/monthdata.php?city=). Data was recorded every hour and was collected using a variety of instruments and measurement protocols (e.g. beta attenuation monitoring, tapered element oscillating microbalances, etc.). The instruments involved were mostly installed at $2.0 \mathrm{~m}$ above ground level. We used the data from 30 representative major cities in China (Fig. 1). The data was 
recorded from January 2014 to December 2018, and we derived monthly averages representing the annual variation in the concentration of fine particulate matter and other parameters across the entire country.

Manning et al., (2018) used aggregated data sources to analyze diurnal $\mathrm{PM}_{2.5}$ cycles using over 17 million hourly measurements recorded at 3,110 sites world-wide (primarily North America, Europe, and East Asia), and thus obtained the global diurnal variation pattern. We sought the approval of these researchers to use their precise and reliable results, which are directly cited in our work presented here. More specifically, the data is used to conduct the correlation analysis with the corresponding diurnal earth-air activity.

\subsection{Monthly/annual and diurnal variations of earth-air pressure}

The earth-air monitoring point used, Dunhuang, in the Gobi Desert in northwestern China, home to the famous Mogao Grottoes ( $40^{\circ} 02^{\prime} 14^{\prime \prime} \mathrm{N}, 94^{\circ} 47^{\prime} 38^{\prime \prime} \mathrm{E}$; altitude 1,350 m, Fig. 1). In this region, the soil porosity is about $20-30 \%$, and $55 \%$ of the soil is medium gravel with its particle size greater than $1.0 \mathrm{~cm}$ (Li et al., 2014). The diurnal hetero-thermo-zone (HTZ) lies at a depth of $0-60 \mathrm{~cm}$, and the annual HTZ corresponds to a depth of about $10-15 \mathrm{~m}$. The water content is $1.0-5.5 \%$. The phreatic water present has a burial depth of over $200 \mathrm{~m}(\mathrm{Li}, 2018)$.

For this work, we monitored the earth-air pressure at this site to a depth of $600 \mathrm{~cm}$, to elucidate the basic annual and diurnal variation pattern in the earth-air pressure. Details of the method employed are outlined below.

A pit was dug to a depth of $600 \mathrm{~cm}$. Calibrated air pressure transmitters (model HD9408T, made in Italy and accurate to $\pm 0.5 \mathrm{hPa}$ at $20^{\circ} \mathrm{C}$ ) were placed in the pit at depths of $10,30,50,100,200,300,400,500$, and $600 \mathrm{~cm}$ below ground. Another one was located $20 \mathrm{~cm}$ above the ground, and data was recorded from all monitors every 30 minutes using a BT805 recorder. As the earth-air pressure is affected by changes in the soil temperature $(\mathrm{Li}, 2018)$, the temperature and relative humidity $(\mathrm{RH})$ were also recorded every hour at every monitoring depth using HOBO-U23-001 sensors (made in USA and accurate to \pm $0.18^{\circ} \mathrm{C}$ between 0 and $50^{\circ} \mathrm{C}$ and $\pm 2.5 \% \mathrm{RH}$ in the range $10-90 \%$ ). Then, the pit was backfilled and the soil tamped down.

\section{Results And Analysis}

\subsection{Annual and diurnal variations of the concentration of fine particulates}

The monthly average concentrations of $\mathrm{PM}_{2.5}, \mathrm{PM}_{10}, \mathrm{SO}_{2}$, and $\mathrm{NO}_{2}$ recorded in the 30 cities are shown in Fig. 2. As can be seen, the concentrations of these pollutants are relatively high in winter and much lower 
in summer (Zhang and Cao, 2015). To some extent, these variations also represented characteristics globally observed (Masiol et al., 2016; Kumar, 2018; Saxena et al., 2017).

The statistical pattern of the global diurnal $\mathrm{PM}_{2.5}$ concentration obtained by Manning et al. (2018) is shown in Fig. 3. There was a $26.19 \%$ diurnal variation in the relative concentration of $\mathrm{PM}_{2.5}$.

\subsection{Annual and diurnal pressure variations in earth-air 3.2.1. Annual pressure variations in earth-air}

The variation of the air pressure recorded by our sensors inside and outside the soil is shown in Fig. 4a. Because some of the values are within a small range, these lines overlap each other.

Earth-air pressure is lower in summer and higher in winter, the difference being about $16 \mathrm{hPa}$. Within 600 $\mathrm{cm}$ of the vadose zone, the earth-air pressure fluctuates with the atmosphere. The daily variation in barometric pressure is shown in Fig. 4b. The monthly average pressure at $10 \mathrm{~cm}$-depth is shown in Fig. 2, which is representative of the behavior of the earth-air pressure. It's consistent with the change pattern of atmospheric pressure, which follows the basic trendline of the annual global atmospheric pressure. The corresponding variations in $\mathrm{RH}$ and temperature are also shown in Fig. 4, $\mathrm{c}$ and $\mathrm{d}$. The $\mathrm{RH}$ recorded at 10 $\mathrm{cm}$ is significantly different from other depths, as it varies under the influence of a small amount of precipitation received. Below $10 \mathrm{~cm}$, the $\mathrm{RH}$ remains $100 \%$ all year round. As seen from Fig. $4 \mathrm{~d}$, the temperature in the upper layer varies markedly with the season, being higher in winter and lower in summer. There also exists a 'temperature hysteresis' phenomenon in the lower layers (Walsh et al., 1991), and, at the same time, the amplitudes of the variational fluctuations decreased. The highest average temperature in the $100-600 \mathrm{~cm}$ depth range occurs in September and corresponds to $19.14^{\circ} \mathrm{C}$; the lowest value, $10.16^{\circ} \mathrm{C}$, occurring in March.

\subsubsection{Diurnal pressure variations in earth-air}

Representative graphs showing the activity of earth-air pressure on a daily timescale are shown in Fig. 5.

Figure 5a shows that the earth-air pressure closely follows the external atmospheric pressure, and is significantly lower at around 19:00. In order to obtain a more accurate assessment of the diurnal characteristics of the earth-air pressure change, the annual pressure change shown in Fig. 4a needs to be taken into account. Take the pressure of $10 \mathrm{~cm}$ to represent the earth-air, conducting a statistical analysis of the daily differences allows the average daily change in pressure to be found, giving the result 4.88 $\mathrm{hPa}$. The average daily earth-air pressure is shown in Fig. 3, presenting obvious bimodal characteristics and a typical global diurnal atmospheric pressure variation (Stolov, 1951). The largest pressure peakvalley difference in the figure is $1.74 \mathrm{hPa}(=862.14-860.40)$ and the smaller one is $0.84 \mathrm{hPa}(=861.97-$ $861.13)$. Clearly, the statistical difference $(4.88 \mathrm{hPa})$ is greater than the average daily pressure difference $(1.74 \mathrm{hPa})$. The main reason for this is that many unsynchronized pressure changes $(4.88-1.74=3.14$ $\mathrm{hPa}$ ) cancel each other out in the process of averaging the daily pressures. Hence, rate of change is 2.80 
$(=4.88 / 1.74)$, another smaller pressure peak-valley difference $(0.84 \mathrm{hPa})$ should be about $2.36 \mathrm{hPa}(=$ $0.84 \times 2.80)$ according to the larger pressure difference change.

As a result of the temperature hysteresis, temperature of the $50-\mathrm{cm}$ layer rises during night time. The amplitude of the variation decreases as the depth increase. The same mechanism is involved here as that responsible for the yearly variation in the HTZ. Below the diurnal HTZ, the temperature remains stable and decreases with depth. Figure $5 \mathrm{~b}$ also shows that the average temperature of the $60-\mathrm{cm}$ layer has a maximum value of $31.53^{\circ} \mathrm{C}$ and minimum of $26.67^{\circ} \mathrm{C}$.

\subsection{Quantitative estimation of earth-air breathing and correlation analysis}

As the soil temperature rises, adsorbed air undergoes desorption, so the earth-air pressure increases. Conversely, when the soil cools down, it absorbs air which leads to a decrease in pressure. Naturally, this process is intermingled with the thermal expansion/contraction of the air in the soil. Therefore, there is a mechanism of 'autonomous breathing' of the earth-air in the diurnal and annual HTZ, which is caused by the temperature change. Conducting monitoring experiments in a temperature/humidity-controlled chamber allows a quantitative estimation of the contribution which autonomous breathing made in the diurnal and annual HTZ.

We start by estimating the volume of earth-air involved in autonomous breathing at a depth of $60 \mathrm{~cm}$ (i.e. in the diurnal HTZ). Based on previous experiments carried out in the temperature/humidity-controlled chamber, the monitoring results obtained for pressure, $P$, were fitted to simple functions of temperature, $T$ (in ${ }^{\circ} \mathrm{C}$ ). For example, for the saline soil found in the Gobi Desert (with a water content of $1.8 \%$ ) we found (Li, 2018):

$P=4.753 T+822.16\left(R^{2}=0.9821 ; P=0.01\right)(1)$

We could then use the Boyle's law, $P_{1} V_{1}=V_{2} P_{2}$, in the form

$\Delta V=V_{1}-V_{2}=V_{1}\left(P_{2}-P_{1}\right) / P_{2}=V_{0} \Delta P / P_{2}(2)$

to calculate the amount of earth-air released. Here, $P_{1}$ is the earth-air pressure when volume is $V_{1}, P_{2}$ is the earth-air pressure when volume is $V_{2}$, and $V_{0}$ is the pore space of the vadose zone. So, the volume of earth-air released from a certain depth $(D)$ of soil per unit cross-sectional area is, $\Delta V=D \times 1$, so

$D=\Delta V / 1=\Delta V=V_{0} \Delta P / P_{2}=\operatorname{tn} \Delta P / P_{2}(3)$

where $n$ is the porosity (taken to be 25\%) and $t$ is the thickness of the diurnal HTZ (taken to be $60 \mathrm{~cm}$ ). According to Fig. $5 \mathrm{~b}$, the highest daily average temperature is $31.53^{\circ} \mathrm{C}$, and the lowest is $26.67^{\circ} \mathrm{C}$. Substituting these values into Eqs. (1)- (3) yields,

$P_{1}=4.753 T_{1}+822.16=4.753 \times 26.67+822.16=948.92(\mathrm{hPa})$ 
$P_{2}=4.753 T_{2}+822.16=4.753 \times 31.53+822.16=972.02(\mathrm{hPa})$

$\Delta P=P_{2}-P_{1}=23.10(\mathrm{hPa})$

$D=\operatorname{tn} \Delta P / P_{2}=600 \times 0.25 \times 23.10 / 972.02=3.57(\mathrm{~mm})$

That is, the diurnal HTZ releases $3.57 \mathrm{~mm} / \mathrm{d}$ of earth-air.

Next, the temperatures $T_{\mathrm{Mar}}=10.16^{\circ} \mathrm{C}$ and $T_{\text {Sept }}=19.14^{\circ} \mathrm{C}$ are substituted into Eqs. (1) and (3). We thus find that the amount of earth-air released from the $600-\mathrm{cm}$ deep layer is $70.11 \mathrm{~mm} / \mathrm{yr}$.

Clearly, on both daily and yearly timescales, the amount of earth-air involved in autonomous breathing is small, and insufficient to cause a change in haze concentration. So, we have to consider the quantity and impact of the air involved in passive breathing. When the atmospheric pressure increases, the earth-air is compressed and atmospheric air will enter into the soil and cause back-mixing (Mecklenburgh and Hartland, 1975). That is, it causes air movement into the soil interface in the opposite direction to the flow. This latter movement is not conducive to dust settling and therefore it greatly increases the concentration of particles in the air (Hartland and Mecklenburgh, 1968; Liu, 2003). When the atmospheric pressure falls, the earth-air will expand and flow out from the earth's surface. Therefore, we can infer that when polluted air enters into the soil, the pollutants may be absorbed and filtered by the soil. When the earth-air flows out from the earth, it may bring a small amount of particulate soil matter; however, the overall particle concentration is low. Therefore, the earth-air which flows out is relatively clean.

We regard the vadose zone as a closed system in the process of atmospheric fluctuation, ignore the diurnal temperature variation in the shallow soil, and regarding the earth-air as an ideal gas with an isothermal process. The amount of passive breathing involved in the atmospheric diurnal/annual fluctuations could also be calculated by Eqs. (2) and (3). According to Eqs. (2) and (3), the thickness and porosity of the local vadose zone affect the quantity of earth-air. However, the $\Delta V$ varies accordingly with the diurnal/annual variation of the atmospheric pressure. Because a typical global diurnal atmospheric pressure variation presents obvious bimodal characteristics (Stolov, 1951), the $\Delta V$ also varied with bimodal characteristics. Therefore, even if the atmospheric pressure at the Mogao Grottoes changed in an abnormal pattern, it is irrelevant to the characteristics of other regions. Moreover, the annual and diurnal atmospheric pressure variations monitored at the Mogao Grottoes are the same as those in the global models, and the annual and diurnal variation models of the earth-air are accepted as globally representative. In this paper, we take the Mogao Grottoes as an example to show the potential influence of the earth-air activity on the haze concentration.

The average annual pressure in the $10-\mathrm{cm}$ soil layer is $861.37 \mathrm{hPa}$. Hence, the actual pressure change involved in the large barometric fluctuation of $4.88 \mathrm{hPa}$ which occurs in the afternoon (Fig. 3) corresponds to a drop from 863.81 to $858.93 \mathrm{hPa}$. The depth of the vadose zone is $200 \mathrm{~m}$, and therefore,

$D=\operatorname{tn} \Delta P / P_{2}=200,000 \times 0.25 \times(4.88 / 858.93)=284.07(\mathrm{~mm})$ 
This meant that $284.07 \mathrm{~mm}$ of earth-air is released into the atmosphere in the afternoon as the outside atmospheric pressure decreases. For the smaller pressure fluctuation $(2.36 \mathrm{hPa})$ which occurs at night, the amount of breathing is,

$D=\operatorname{tn} \Delta P / P_{2}=200,000 \times 0.25 \times 2.36 /(861.37-2.36 / 2)=137.18(\mathrm{~mm})$

The total amount of earth-air released from these two processes is $421.25 \mathrm{~mm}(=284.07+137.18)$. Not included in this calculation was the small unsynchronized pressure changes of $3.14 \mathrm{hPa}$ that canceled each other out in the daily fluctuation statistics. The soil could thus purify the atmospheric air corresponding to at least $153.76 \mathrm{~m}(=365 \times 421.25 / 1000)$ all year round. Similarly, for barometric pressure fluctuations of 10 and $30 \mathrm{hPa}$, the amount of air purified corresponded to 583.86 and 1,772.27 $\mathrm{mm}$ respectively. Therefore, the amount of earth-air activity could easily influence the monitoring of $\mathrm{PM}_{2.5}$ concentration which is carried out at a height of $2.0 \mathrm{~m}$ above ground.

Figure 3 shows that there is a good correlation between the diurnal barometric pressure variation and $\mathrm{PM}_{2.5}$ concentration. A statistical analysis of the data yields a correlation coefficient of $0.84(P=0.01)$. Based on Eq. (2), $\Delta V=V_{0} \Delta P / P_{2}$, where $V_{0}$ is a fixed value, $P_{2}$ is the average atmospheric pressure of $861.61 \mathrm{hPa}$. Thus, the correlation coefficient between $\Delta V$ and $\mathrm{PM}_{2.5}$ concentration also is 0.84 . Clearly, the $\mathrm{PM}_{2.5}$ concentration varies-in the same way as the diurnal barometric pressure and volume passive breathing, all of them having bimodal characteristics.

To clarify this picture, the barometric pressure drops from 23:00 onwards, and relatively clean earth-air flows out from the soil, reducing the $\mathrm{PM}_{2.5}$ concentration. At 5:00, the barometric pressure begins to rise and the earth-air becomes compressed so that some of the atmosphere enters the soil and causes backmixing. Due to the increase in atmospheric pressure, the atmospheric air near the surface also contracted, so the concentration of $\mathrm{PM}_{2.5}$ is increased.

The contraction and expansion of the external atmosphere as the pressure fluctuates is an important reason why the pollutant concentration changes. However, the diurnal fluctuation in atmospheric pressure $\Delta P / P$ which also causes the $P M_{2.5}$ concentration to change, is usually less than $5.73 \%$ ( $\triangle P$ is the daily atmospheric difference, $4.94 \mathrm{hPa}$, and $P$ is the average atmospheric pressure, $861.61 \mathrm{hPa}$ ). Even at low latitudes where the diurnal atmospheric fluctuations are around $20 \mathrm{hPa}$, the diurnal fluctuation rate does not exceed $2.3 \%$. Clearly, such effects are incapable to cause the $26.19 \%$ diurnal variation in $\mathrm{PM}_{2.5}$ concentration shown in Fig. 3 (Manning et al., 2018). Therefore, it is the back-mixing and flow of clean earth-air from the ground that increases or reduces the $\mathrm{PM}_{2.5}$ concentration, causing the large fluctuation range observed in the diurnal variation.

From 10:00 to 16:00, the barometric pressure drops, and cleaner earth-air flows out. At the same time, the atmosphere expands and, therefore, the $\mathrm{PM}_{2.5}$ concentration decreases. From 16:00 onwards, the atmospheric pressure begins to rise, and the atmosphere enters the soil and causes back-mixing. Meanwhile, the atmosphere is compressed and so the $\mathrm{PM}_{2.5}$ concentration increase. At 23:00, the 
pressure and $\mathrm{PM}_{2.5}$ concentration reached another peak, after which they decrease again until 5:00 and the next cycle begins.

It should be noted that Dunhuang uses Beijing time, which is 1 hour and 41 minutes earlier than the local time. Since the change of the atmosphere is a process and air quality monitoring instruments were mostly placed at $2.0 \mathrm{~m}$ above ground, it could take some time for the earth-air to migrate from the surface to such height to be recorded. In other words, there should be a time lag between the $\mathrm{PM}_{2.5}$ concentration and air pressure recorded, and about 1 hour and 41 minutes is appropriate.

In Fig. 2, the correlation between the average atmospheric pressure and $\mathrm{PM}_{2.5}, \mathrm{PM}_{10}, \mathrm{SO}_{2}$, and $\mathrm{NO}_{2}$ concentrations yield correlation coefficients $(P=0.01)$ of $0.82,0.85,0.73$, and 0.94 respectively. Based on Eq. (2), the correlation coefficient between $\Delta V$ and $\mathrm{PM}_{2.5}, \mathrm{PM}_{10}, \mathrm{SO}_{2}$, and $\mathrm{NO}_{2}$ concentration also is 0.84 , $0.82,0.85,0.73,0.94$, respectively.

The annual fluctuation range of the atmospheric pressure is about $16 \mathrm{hPa}$, resulting in a release of $934.72 \mathrm{~mm}$ of earth-air. Although the concentration of particles could be theoretically reduced by a certain amount, considering the yearly timescale involved, the small amounts involved are insufficient to have a decisive impact on the concentration of atmospheric pollutants throughout the year. Also, the atmospheric expansion, caused by a decrease in the atmospheric pressure, partly contributes to the reduction of haze concentration. However, as previously calculated, it is disproportionate to the change of concentration, and its impact is minimal.

In winter, not only are the barometric air pressures higher, but also the soil temperatures. In fact, the temperature difference between the inner soil and outside air is up to $20^{\circ} \mathrm{C}$. When the external atmosphere enters the soil (5:00-10:00 and 16:00-23:00), the air expands and causes a stronger back-mixing. Higher pressure is also conducive to back-mixing (Mecklenburgh and Hartland, 1975; Lim et al., 1995); the atmospheric pressure in winter is high, therefore, back-mixing is promoted.

Conversely, in summer, apart from the atmospheric pressure being lower and producing a weaker backmixing effect, the soil temperature is lower than that of the atmosphere. Therefore, when the relatively warm atmospheric air moves into the soil, it will cool down and contract. In addition, the entirety of the earth-air in the annual HTZ will also cool down and contract when it moves downwards (Fig. 4d). Thus, the atmosphere can more readily enter the soil and reduce the effect of back-mixing. Furthermore, the soil would be able to contain a larger amount of air in its pores, so the soil could absorb a larger amount of pollution from the atmosphere when the pressure is increasing. When the atmospheric pressure decreases, the clean earth-air will flow out. This reduces the pollution concentration, hence lowers the concentration of haze in the atmosphere on a macroscopic level in summer. Therefore, the annual changes in the pressure and temperature seriously affect the amount and efficiency of the haze-cleaning activity of the soil. It is therefore an important cause of seasonal haze variation.

Overall, autonomous breathing has little direct impact on haze as its effects are obscured by the larger passive-breathing effect. Therefore, passive breathing plays a crucial role in the formation of diurnal haze 
patterns. Furthermore, the back-mixing effect has an important impact on the annual change in haze patterns.

\section{Discussion}

It should be pointed out that the haze concentration and earth-air monitoring data do not match in time and space. Although the amplitude of the atmospheric fluctuation, the thickness and porosity of the vadose zone are different in different places, these aspects affect the amount of the passive breathing of the earth-air. However, since the annual variation of the haze concentration in 30 cities and the variation of earth-air in the Mogao Grottoes were both globally representative, and the variation patterns of the haze and atmospheric pressure on yearly and daily scales are stable, the correlation between the earth-air and the haze of the preliminary results is still a valid reference in exploring the formation of haze patterns. Based on Eq. (2) and the variation amplitude of atmospheric pressure and local vadose zone conditions such as porosity and thickness, we can provide guidance for the prediction of haze.

The good correlation between the annual/diurnal cycles of the barometric pressure and $\mathrm{PM}_{2.5}$ concentration can be attributed to the synchronous spatio-temporal patterns that occur in the solar heating. A local $\mathrm{PM}_{2.5}$ variation is associated with air advection and vertical convection. Changes in the large-scaled atmospheric circulation led to varying weather conditions represented by the air pressure variation. The variation in pressure implies different synoptic weather that mainly determines air diffusion conditions and modulates the $\mathrm{PM}_{2.5}$ concentration. So, the synergic variations of $\mathrm{PM}_{2.5}$ and earth-air pressure result from the fluctuation of large-scaled atmospheric circulation, both of which are the two sides of a coin. However, the contribution of the purified earth-air volume is relatively small $(421.25 \mathrm{~mm} / \mathrm{d})$ compared with the haze of several hundred meters. The haze concentration is mainly determined by a change of the boundary layer, with the diurnal variation above $1000 \mathrm{~m}$ (Manning et al., 2018). However, partially because the $\mathrm{PM}_{2.5}$ monitoring site was close to the ground $(2.0 \mathrm{~m})$, the earth-air made the diurnal variability of $\mathrm{PM}_{2.5}$ similar to the change of the barometric pressure with bimodal characteristics, rather than the unimodal height of the planetary boundary layer. The temporal variation in the $\mathrm{PM}_{2.5}$ concentration has long been attributed to the dynamics of the boundary layer and anthropogenic emissions in general (Huang et al., 2015; Fontes et al., 2017). The height of the planetary boundary layer is higher in summer and during daytime, which leads to lower $\mathrm{PM}_{2.5}$ concentrations (Manning et al., 2018).

In addition, domestic heating requirements and biomass burning by farmers in winter increase the emission of anthropogenic pollutants (Li et al., 2017; Fontes et al., 2017). Vehicle emissions during rush hours enhance the $\mathrm{PM}_{2.5}$ concentration on a diurnal timescale (Kim et al., 2002; Zhao et al., 2009; Manning et al., 2018). Moreover, in the process of large-scaled urbanization, people use materials such as cement, stone, and asphalt to seal the ground through landscape and urban constructions. An increase in the natural-ground sealing forms more impervious surface, which inevitably reduces the exchanging 
volume of the earth-air, causing aggravated haze. Therefore, the environmental conditions inside and outside the soil together with human activities are responsible for the observed haze patterns.

The Chinese terminology for haze is ' $\|$ ' (fog and haze). This is because the ancient Chinese monitored the earth-air, or hou-qi (Li, 2018), and, therefore, clearly understood the situation when the word was created. The earth-air with saturated water vapor (Fig. 4c) flows out, forms the fog and brings fine particles up, forming the haze. These particles typically consist of crust elements locally buried in the soil (Huang et al., 2014), and even those from deeper layers that have penetrated the surface, making the crust one of the important sources of haze-causing material (Sun et al., 2014). However, compared with serious anthropogenic pollutions, crust elements account for a small proportion. Therefore, from time immemorial, haze has the same origin as fog.

Moreover, except crust elements, the earth-air will blow out $\mathrm{SO}_{2}, \mathrm{NO}_{2}$, aerosols, and salts from the soil (Hinds, 1999). Since the climate in winter is relatively dry, salts such as sulfates and nitrates form crystals more readily (Wang et al., 2015). As the RH is saturated in the soil (Fig. 4c), the high moisture content of the soil will amplify the concentration of pollutants (Tie et al., 2017; Huang et al., 2014; Cheng et al., 2016), and $\mathrm{SO}_{2}$ and $\mathrm{NO}_{2}$ will be produced underground by microbes, e.g. $\mathrm{NO}_{2}$ may be produced by nitrifying bacteria (Gourneau et al., 1980). Over time, this filtration effect will cause the concentrations of the pollutants trapped in the soil to become large. The pollutants may undergo chemical combination, decomposition, or biochemical processes, etc. in the humid soil environment, and thus generate other pollutants. Therefore, the soil will become an important place for the formation of secondary pollutants. As the earth-air comes out of the soil, it will therefore take these pollutants out of the ground with earthair, increasing the concentration of secondary pollutants in the atmosphere. Therefore, there is a certain amount of secondary pollution in the haze (Huang et al., 2014; Li et al., 2018) which results in the samples collected in the morning and evening showing signs of universal sulfuration. The mineral particles mainly come from the crust in Harbin, and the average value of the S/Ca ratio is 73 times that of the sample taken at 12:00 PM (Liu et. al., 2010).

In addition, if the atmospheric pressure undergoes a sudden dramatic drop, the earth-air would go through a rapid outburst and activate a large quantity of soil particles. However, under the circumstance of the excellent air ventilation, it would have little effect on the concentration of $\mathrm{PM}_{2.5}$. On the contrary, the concentration of particulate matters would increase in the dust storm. Under more 'normal' urban circumstances, when the atmospheric pressure decreases, the haze concentration decreases, and vice versa. Thus, the occurrence of haze is closely related to the rate at which the atmospheric pressure changes.

\section{Conclusions}

Statistics shows that the global concentration of fine particulate matter is higher in winter and lower in summer on a yearly timescale, and it presents bimodal characteristic patterns on a daily timescale. The earth-air monitoring results at the Mogao Grottoes show that the earth-air pressure follows similar trends

Page $11 / 19$ 
as the global model of atmospheric pressure, and the volume of earth-air passive breathing varies with atmospheric pressure. Thus, there is a high correlation between the earth-air passive breathing and the $\mathrm{PM}_{2.5}$ concentration. There is also a feasible mechanism of the correlation between earth-air passive breathing and haze pattern formation:

On a daily timescale, when the atmospheric pressure increases, the atmospheric volume is compressed, back-mixing occurs, and the $\mathrm{PM}_{2.5}$ concentration increases. At the same time, the earth-air is also compressed and atmospheric pollution enters into the soil, in which it is filtered and absorbed. When the atmospheric pressure decreases, the atmospheric volume increases, and the clean earth-air flows out. The detected atmospheric $\mathrm{PM}_{2.5}$ concentration therefore decreases, forming a pattern which is synchronized with the diurnal change in the earth-air passive breathing and shows bimodal characteristics. On a yearly timescale, the soil cleans a larger volume of air in the summer. Furthermore, the pressure and temperature in winter makes part of the atmosphere enter the soil, causing stronger back-mixing. This makes it more difficult for anthropogenic pollution to settle, and greatly weakens the filtration and purification function of the soil. Thus, the concentration of haze is higher in winter.

\section{Declarations}

\section{Acknowledgments:}

This work was supported by the National Natural Science Foundation of China (41967029); The National Key Research and Development Program of China (2019YFC1520903), and the Gansu Province Science and Technology Plan Project (20JR5RA056). The author would like to thank China's Air Quality Online Monitoring and Analysis Platform for facilitating the required historical data queries and Max I. Manning for generously supplying his global data on diurnal $\mathrm{PM}_{2.5}$ concentration. Data available in the supplemental material.

\section{References}

1. Cheng, Y., Zheng, G., Wei, C., Mu, Q., Zheng, B., Wang, Z., Gao, M., Zhang, Q., He, K., Carmichael, G., 2016: Reactive nitrogen chemistry in aerosol water as a source of sulfate during haze events in China. Sci. Adv. 2, e1601530-e1601530.

2. Fontes, T., Li, P., Barros, N., Zhao, P., 2017: Trends of PM2.5 concentrations in China: A long term approach. J. Environ. Manage. 196, 719-732.

3. Goreau, T.J., Kaplan, W.A., Wofsy, S.C., McElroy, M.B., Valois, F.W., Watson, S.W., 1980: Production of $\mathrm{NO}_{2}$ and $\mathrm{N}_{2} \mathrm{O}$ by nitrifying bacteria at reduced concentrations of oxygen. Appl. Environ. Microbiol. 40, 526-532.

4. Hartland, S., Mecklenburgh, J. C., 1968: The concept of backmixing. Chemical Engineering Science, 23: $186-187$. 
5. Hao, H., Guo, Q., 2018: Spatial and temporal characteristics of PM2.5 and source apportionment in Wuhan, in: IOP Conference Series: Earth and Environmental Science.

6. He, Q., Geng, F., Li, C., Mu, H., Zhou, G., Liu, X., Wei, G., Wang, Y., Cheng, T., 2018: Long-term variation of satellite-based PM2.5 and influence factors over East China. Sci. Rep. 8.

7. Hinds, W.C., 1999: Aerosol technology: properties, behavior, and measurement of airborne particles. J. Aerosol Sci. 31, 1121-1122.

8. Huang, R., Zhang, Y., Bozzetti, C., Ho, K., Cao, J. J., Han, Y., Daellenbach, Kaspar R., Slowik, Jay G., Platt, Stephen M., Francesco, C., 2014: High secondary aerosol contribution to particulate pollution during haze events in China. Nature 514, 218-222.

9. Kim, S., Shen, S., Sioutas, C., 2002: Size distribution and diurnal and annual trends of ultrafine particles in source and receptor sites of the Los Angeles basin. J. Air Waste Manag. Assoc. 52, 297307.

10. Kumar, J., 2018: Haze formation during winter in Delhi. Environ. Asia 11, 213-220.

11. Li, H., Wang, W., Wu, F., Zhan, H., Zhang, G., Qiu, F., 2014: A new sand-wedge-forming mechanism in an extra-arid area. Geomorphology, 211, 43-51.

12. Li, H., 2018: Exploring the source and potential of earth-air pulsation using a closed system. Earth Interact. 22, 1-12.

13. Li, H., Zhan, H., 2018: The characteristics and mechanism of the formation of earth-air pulsation in extremely arid areas. J. Geophys. Res. Atmospheres 123. 10,872-10,880. https://doi.org/10.1029/ 2018JD028870

14. Li, H., Zhan, H., Wang, X., 2021. Effect of earth-air breathing on evaporation of deeply-buried phreatic water in extremely arid regions. Hydrological Processes. 2021, 35(4). https://doi.org/DOI: 10.1002/hyp.14078

15. Li, J., Wang, G., Wu, C., Cao, C., Ren, Y., Wang, J., Li, J., Cao, J., Zeng, L., Zhu, T., 2018: Characterization of isoprene-derived secondary organic aerosols at a rural site in North China Plain with implications for anthropogenic pollution effects: Sci Rep 8, 535.

16. Li, X., Ma, Y., Wang, Y., Liu, N., Hong, Y., 2017: Temporal and spatial analyses of particulate matter (PM10 and PM2.5) and its relationship with meteorological parameters over an urban city in northeast China. Atmospheric Res. 198, 185-193.

17. Liang, C., Duan, F., He, K., Ma, Y., 2016: Review on recent progress in observations, source identifications and countermeasures of $\mathrm{PM}_{2.5}$. Environ. Int. 86, 150-70.

18. Lim, K. S., Zhu, J. X., Grace, J. R., 1995: Hydrodynamics of gas-solid fluidization. International Journal of Multiphase Flow, 21(Suppl):141-193.

19. Liu, Y. F., 2003: The design of the masonry slag-off Multi-tube cyclone. Environmental Engineering, 6 : 38-39; 3-4 (In Chinese).

20. Liu, Y. F., Shao, L. Yi., Chang, X. X., 2010: Sulfuration character of individual particulates of PM (10). Environmental Science 31(11):2555-2562. 
21. Manning, M.I., Martin, R.V., Hasenkopf, C., Flasher, J., Li, C., 2018: Diurnal patterns in global fine particulate matter concentration. Environ. Sci. Technol. Lett. 5, 687-691.

https://doi.org/10.1021/acs.estlett.8b00573

22. Masiol, M., Hopke, P.K., Felton, H.D., Frank, B.P., Rattigan, O.V., Wurth, M.J., Laduke, G.H., 2016: Source apportionment of PM 2.5 chemically speciated mass and particle number concentrations in New York City. Atmos. Environ. 148, S1352231016308512.

23. Matthew, R., Allen, D.T., Collins, D.R., Fraser, M.P., 2004: Daily, annual, and spatial trends in PM2.5 mass and composition in Southeast Texas. Aerosol Sci. Technol. 38, 14-26.

24. Mecklenburgh, J. C., Hartland, S., 1975: The Theory of Backmixing. London: Wiley, 17-256.

25. Miao, L., Liao, X.N., Wang, Y.C., 2016: Diurnal variation of PM2.5 mass concentration in Beijing and influence of meteorological factors based on long term date. Environ. Sci. 8, 2836-2846.

26. Miyazaki, Y., Aggarwal, S.G., Singh, K., Gupta, P.K., Kawamura, K., 2009: Dicarboxylic acids and watersoluble organic carbon in aerosols in New Delhi, India, in winter: Characteristics and formation processes. J. Geophys. Res. Atmospheres 114.

27. Nilson, R.H., Peterson, E.W., Lie, K.H., Burkhard, N.R., Hearst, J.R., 199: Atmospheric pumping: a mechanism causing vertical transport of contaminated gases through fractured permeable media. Jour. Geophys. Res, 96(B13), 21933.

28. Paul J, L., Panos G, G., 2011: New Jersey: A case study of the reduction in urban and suburban air pollution from the 1950s to 2010. Environ. Health Perspect. 119, 1351-1355.

29. Saxena, M., Sharma, A., Sen, A., Saxena, P., Saraswati, Mandal, T.K., Sharma, S.K., Sharma, C., 2017: Water soluble inorganic species of PM10 and PM2.5 at an urban site of Delhi, India: Annual variability and sources. Atmospheric Res. 184, 112-125.

30. Seinfeld, J.H., 2004: Air pollution: A half century of progress. Aiche J. 50, 1096-1108.

31. Song, G., Min, H., Zamora, Misti L., Jianfei, P., Dongjie, S., Jing, Z., Zhuofei, D., Zhijun, W., Min, S., Limin, Z., 2014a: Elucidating severe urban haze formation in China. Proc. Natl. Acad. Sci. U. S. A. $111,17373$.

32. Song, L.C., Gao, R., Ying, L.I., Wang, G.F., 2014b: Analysis of China's haze hays in the winter half-year and the climatic background during 1961-2012. Adv. Clim. Change Res. 5, 1-6.

33. Stolov, H. L., 1951: The semidiurnal tidal oscillation of the Earth's atmosphere. American Journal of Physics 19, 403-410.

34. Su, T., Xu, M., Zhou, X., Yang, Z., Yuan, J., Zhang, H., 2015: Study on the variation characteristics of haze weather in Hubei Province during 1980-2012. Agric. Sci. Technol. 176-181.

35. Sun, Y., Jiang, Q., Wang, Z., Fu, P., Li, J., Yang, T., Yin, Y., 2014: Investigation of the sources and evolution processes of severe haze pollution in Beijing in January 2013. J. Geophys. Res. Atmospheres 119, 4380-4398.

36. Tie, X., Huang, R.J., Cao, J., Zhang, Q., Cheng, Y., Su, H., Chang, D., Pöschl, U., Hoffmann, T., Dusek, U., 2017: Severe pollution in China amplified by atmospheric moisture. Sci. Rep. 7, 15760. 
37. Walsh, S.J., Vitek, J.D., Panciera, S.E., 1991: Variability of soil temperature: A spatial and temporal analysis. J. Geogr. 90, 82-90.

38. Wang, G., Zhang, R., Gomez, M.E., Yang, L., Levy, Z.M., Hu, M., Lin, Y., Peng, J., Guo, S., Meng, J., 2016 : Persistent sulfate formation from London fog to Chinese haze. Proc. Natl. Acad. Ofences U. S. Am. $48,13630-13635$.

39. Wang, Y., Zhang, Qianqian, Jiang, J., Zhou, W., Wang, B., He, K., Duan, F., Zhang, Qian, Philip, S., Xie, Y., 2015: Enhanced sulfate formation during China's severe winter haze episode in January 2013 missing from current models. J. Geophys. Res. Atmospheres 119, 10,425-10,440.

40. Weingartner, E., Nyeki, S., Baltensperger, U., 1999: Annual and diurnal variation of aerosol size distributions $(10<\mathrm{D}<750 \mathrm{~nm})$ at a high-alpine site (Jungfraujoch $3580 \mathrm{~m}$ asl). J. Geophys. Res. Atmospheres 104, 26809-26820.

41. Xu, J., Wang, Z., Yu, G., Sun, W., Xiang, Q., Ren, J., Qin, D., 2013: Annual and diurnal variations in aerosol concentrations at a high-altitude site on the northern boundary of Qinghai-Xizang Plateau. Atmospheric Res. 120-121, 240-248.

42. Yang, Y.R., Liu, X.G., Qu, Y., An, J.L., Jiang, R., Zhang, Y.H., Sun, Y.L., Wu, Z.J., Zhang, F., Xu, W.Q., 2015: Characteristics and formation mechanism of continuous hazes in China: a case study during the autumn of 2014 in the North China Plain. Atmospheric Chem. Physics15142015-07-23 15, 1098711029.

43. Zhang, Z., Xu, X., Qiao, L., Gong, D., Kim, S.J., Wang, Y., Mao, R., 2018: Numerical simulations of the effects of regional topography on haze pollution in Beijing. Sci. Rep. 8, 5504.

44. Zhang, Y.-L., Cao, F., 2015. Fine particulate matter (PM2.5) in China at a city level. Sci. Rep. 5, 14884.

45. Zhao, X., Zhang, X., Xu, X., Xu, J., Meng, W., Pu, W., 2009. Seasonal and diurnal variations of ambient PM2.5 concentration in urban and rural environments in Beijing. Atmos. Environ. 43, 2893-2900. https://doi.org/10.1016/j.atmosenv.2009.03.009

\section{Figures}




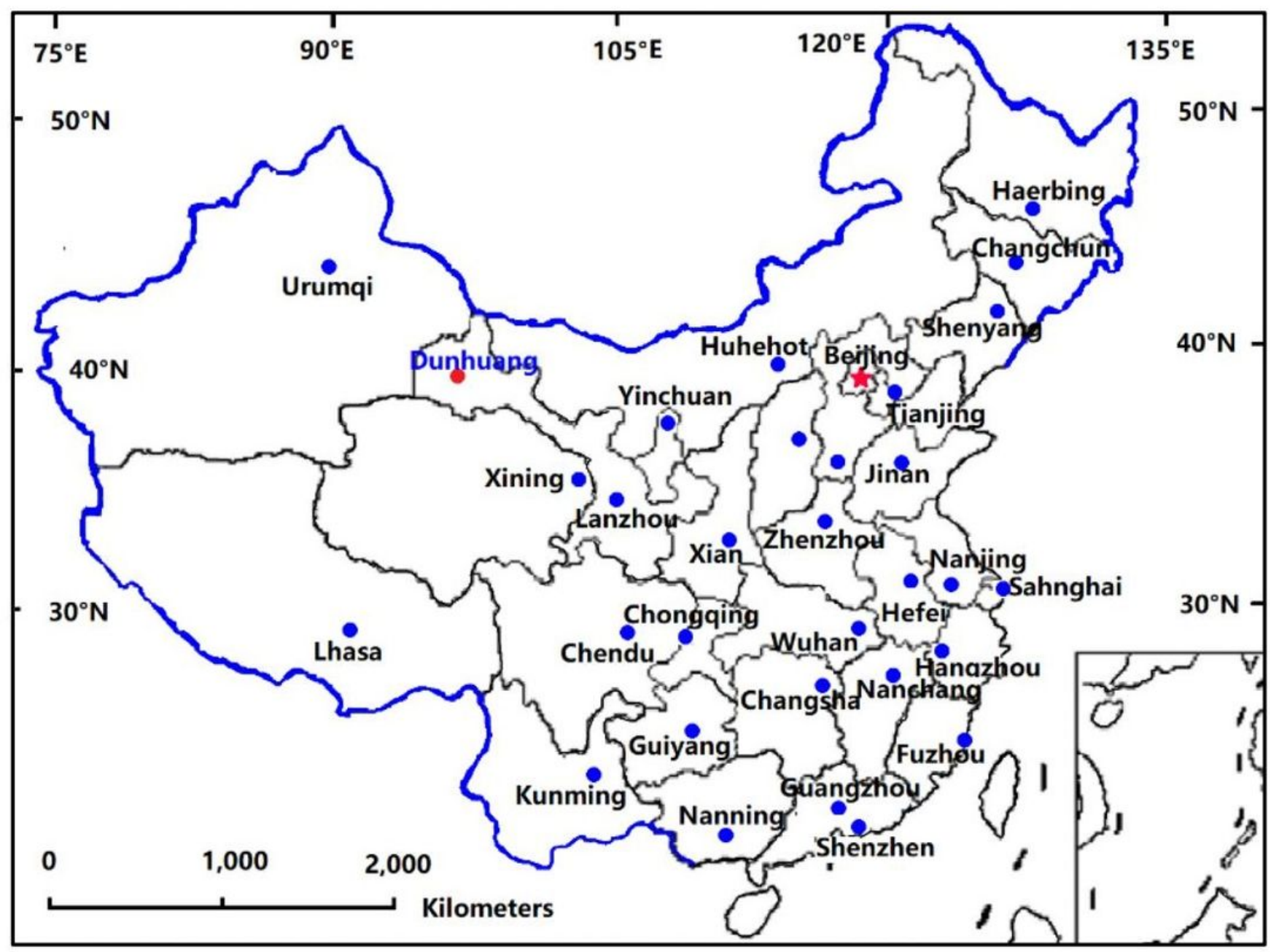

Figure 1

Map showing the locations of the 30 cities whose air-monitoring data is used in this study and that of the earth-air monitoring point (Dunhuang). Note: The designations employed and the presentation of the material on this map do not imply the expression of any opinion whatsoever on the part of Research Square concerning the legal status of any country, territory, city or area or of its authorities, or concerning the delimitation of its frontiers or boundaries. This map has been provided by the authors. 
$\rightarrow \mathrm{PM}_{2.5} \rightarrow \mathrm{PM}_{10} \rightarrow-\mathrm{SO}_{2} \rightarrow-\mathrm{NO}_{2} \rightarrow 10 \mathrm{~cm}$ pressure

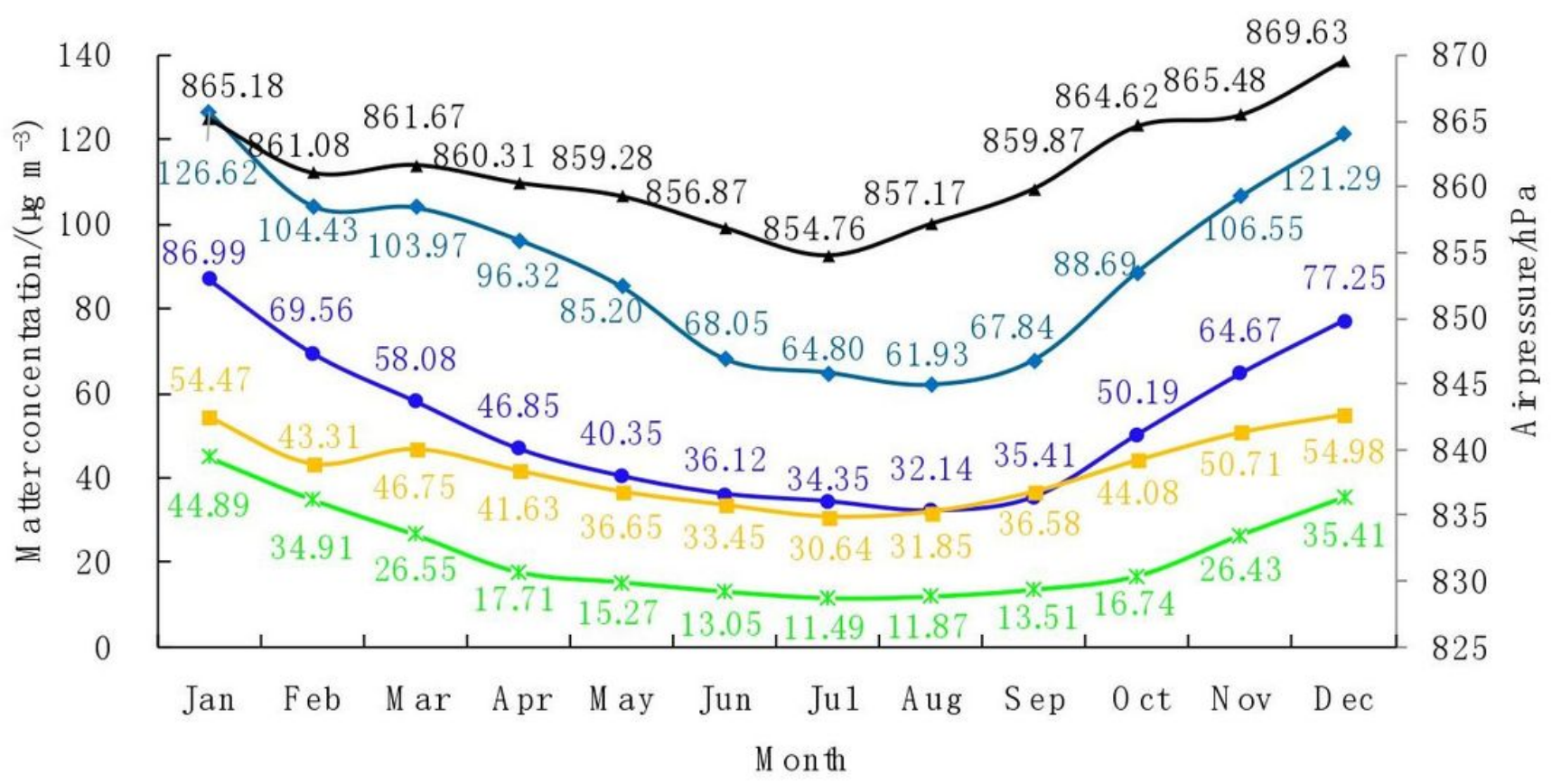

Figure 2

Monthly average of PM2.5, PM10, SO2, and NO2 concentrations for the 30 cities shown in Fig. 1 from 2014 to 2018 and the earth-air pressure at a depth of $10 \mathrm{~cm}$ (2014).

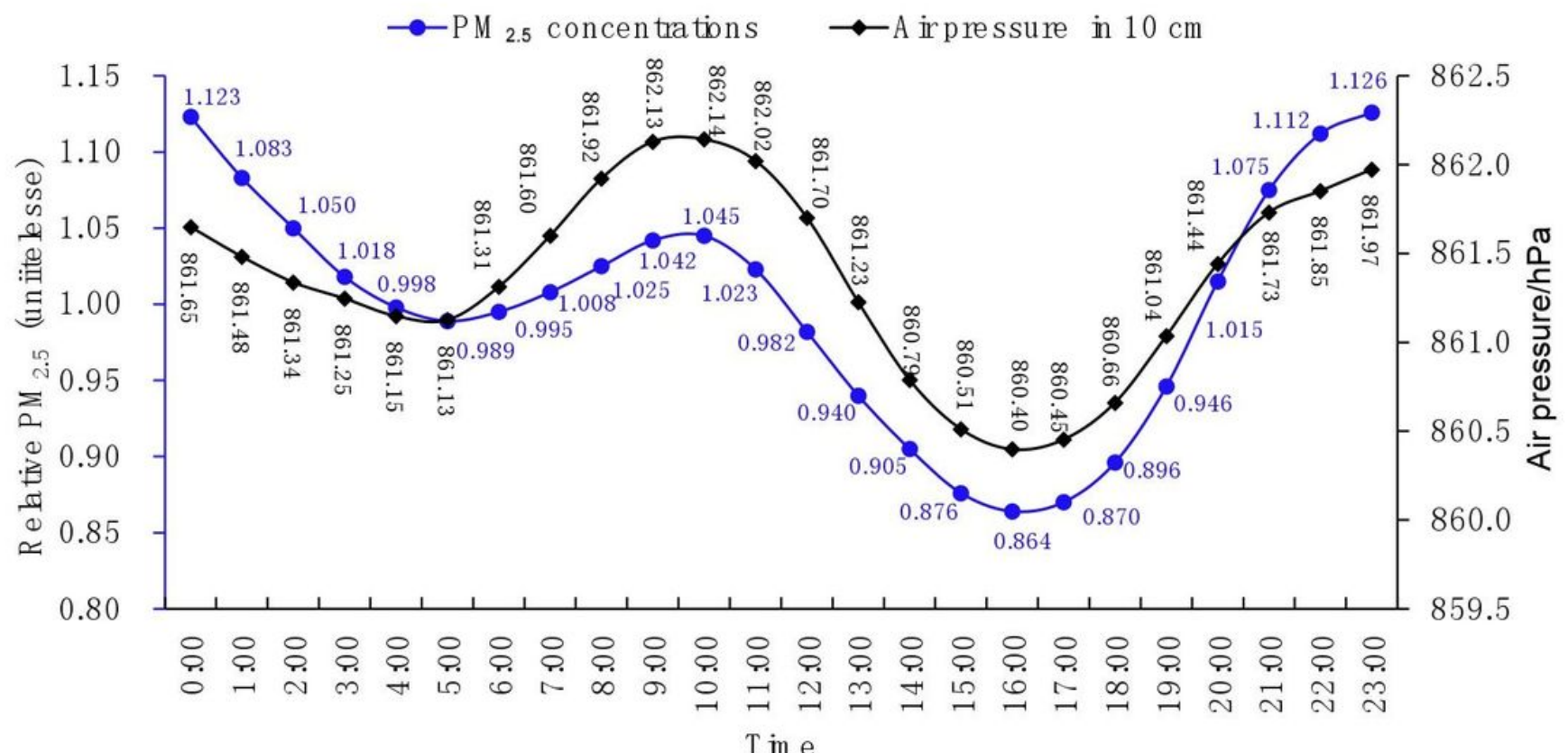

Figure 3 
The global diurnal pattern in PM2.5 concentration and the diurnal variation in the earth-air pressure difference in the $10 \mathrm{~cm}$ layer. Plots showing the temporal relationship between PM2.5 concentration which highlights the direct influence of earth-air $(10 \mathrm{~cm})$ on PM2.5 concentration. Dunhuang uses Beijing time, which is 1 hour and 41 minutes earlier than the local time used to record PM2.5 values.
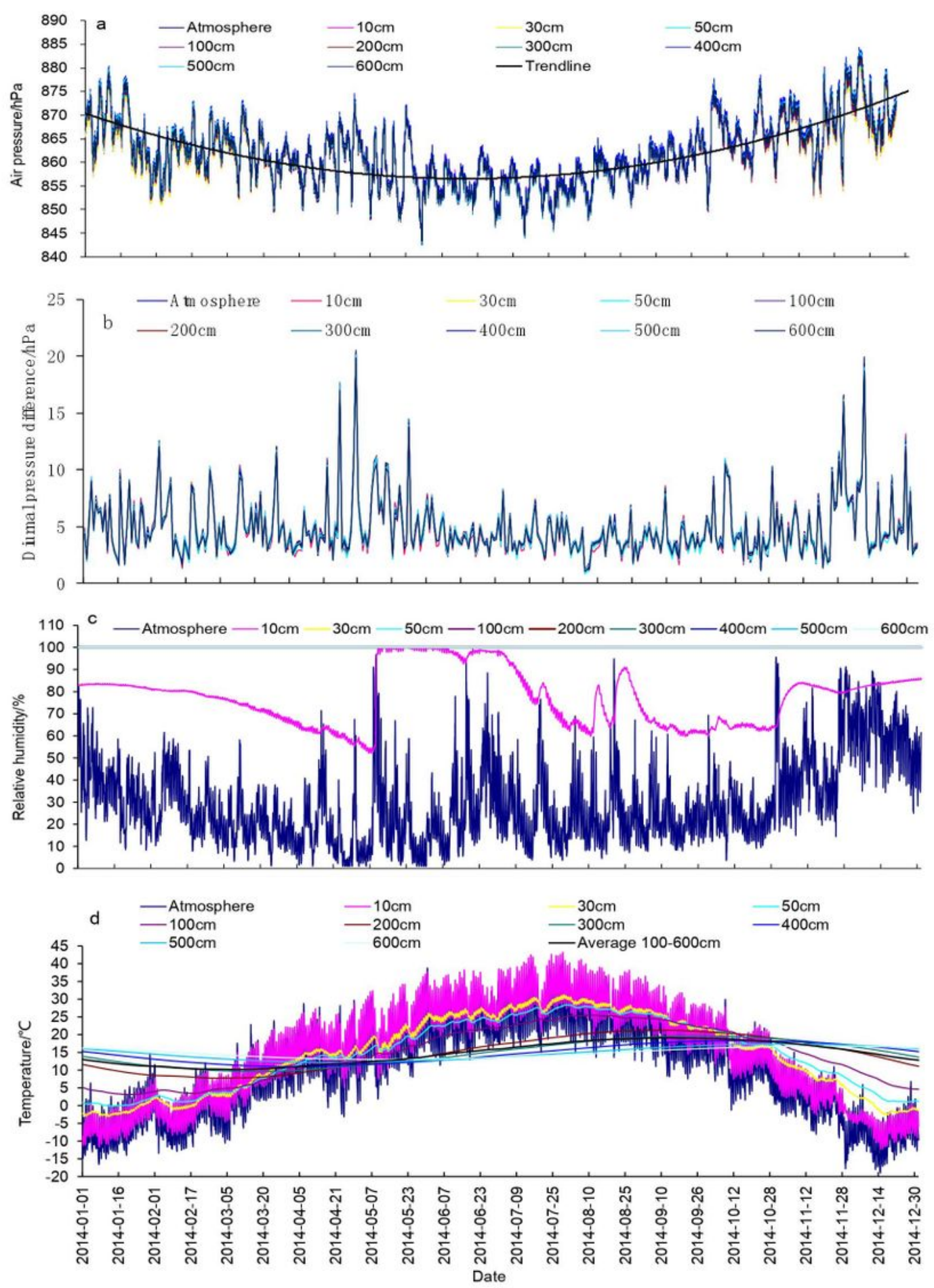

Figure 4 
The annual variations in: (a) air pressure, (b) diurnal pressure difference, (c) $\mathrm{RH}$, and (d) temperature, inside and outside the soil.
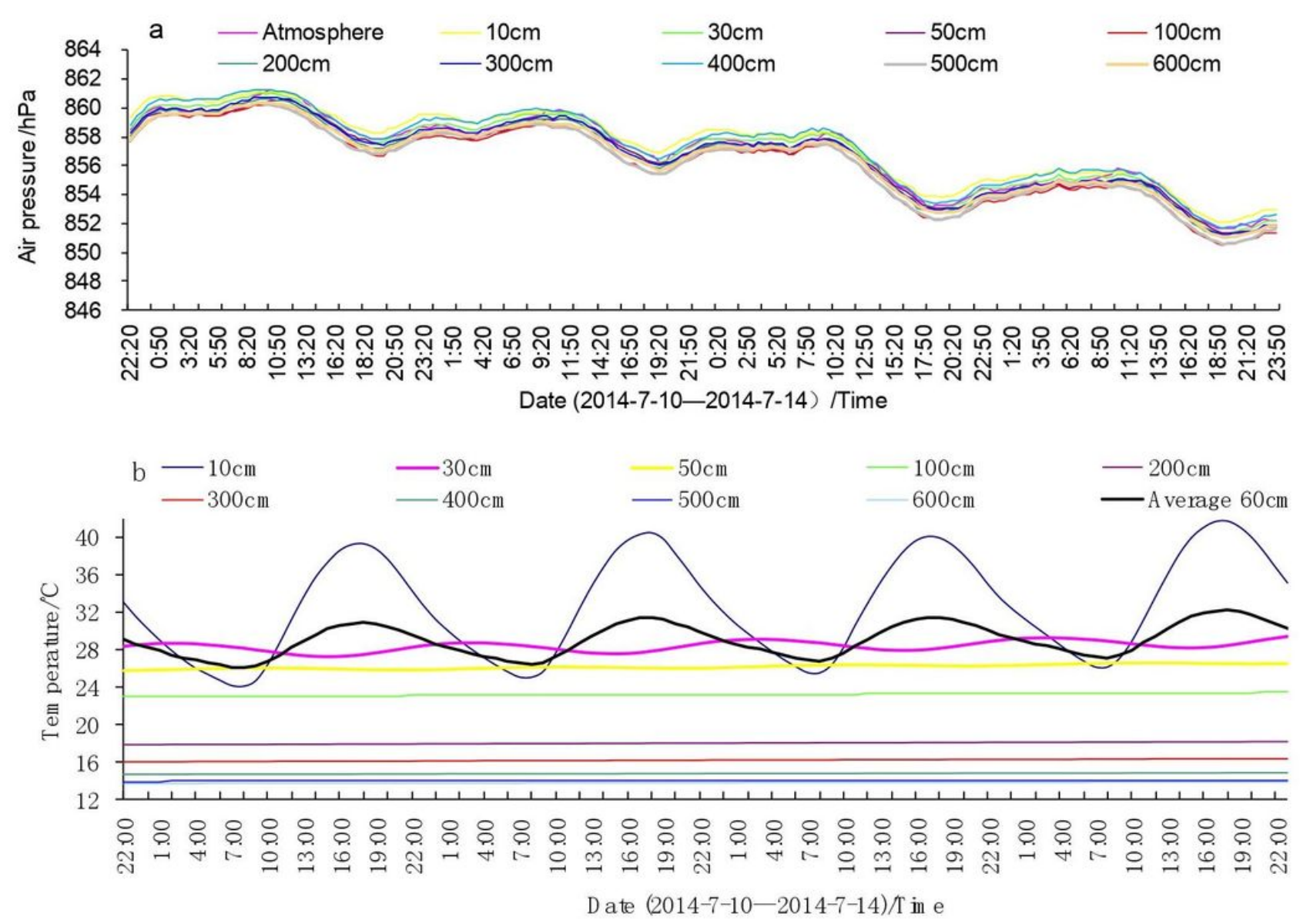

Figure 5

The diurnal variations in: (a) air pressure and (b) temperature.

\section{Supplementary Files}

This is a list of supplementary files associated with this preprint. Click to download.

- DatainBriefFig.25.xlsx 